\title{
Supporting students' mental health in schools: what do teachers want and need?
}

Article

Accepted Version

Shelemy, L., Harvey, K. and Waite, P. (2019) Supporting students' mental health in schools: what do teachers want and need? Emotional and Behavioural Difficulties, 24 (1). pp. 100116. ISSN 1363-2752 doi:

https://doi.org/10.1080/13632752.2019.1582742 Available at https://centaur.reading.ac.uk/82380/

It is advisable to refer to the publisher's version if you intend to cite from the work. See Guidance on citing.

To link to this article DOI: http://dx.doi.org/10.1080/13632752.2019.1582742

Publisher: Taylor and Francis

All outputs in CentAUR are protected by Intellectual Property Rights law, including copyright law. Copyright and IPR is retained by the creators or other copyright holders. Terms and conditions for use of this material are defined in the End User Agreement.

www.reading.ac.uk/centaur 
Central Archive at the University of Reading

Reading's research outputs online 
Supporting students' mental health in schools: what do teachers want and need?

Lucas Shelemy $^{\mathrm{a} *}$, Kate Harvey ${ }^{\mathrm{a}}$ and Polly Waite

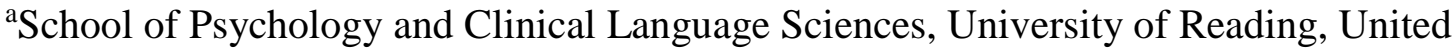
Kingdom

*Corresponding author: 1.shelemy@pgr.reading.ac.uk; +44 (0)118 378 8523; ORCID Lucas Shelemy: 0000-0002-2831-3434 
Supporting students' mental health in schools: what do teachers want and need?

There is a growing expectation in the UK for teachers to have an understanding of common mental health problems in young people. This study aims to identify the training needs of secondary school teachers to enable them to adequately support and educate their students around mental health. Nine focus groups, each with between four to eight participants, were conducted with secondary school teachers in the UK. Discussions were centred on the needs and wants of teachers in terms of mental health training, provision and advice. Participants were also shown three online resources as an example of existing training. Thematic analysis was used to structure the data. Participants wanted training on how to identify and provide early support for students who are struggling, without taking on the perceived role of a therapist. Participants also emphasised the strong need for practical, interactive and expert-led training that provides resources that can be adapted to individual settings. Implications and recommendations are discussed.

Keywords: teachers, school, training, focus groups

Word count (inclusive of references, tables and captions): 7903 
Despite the high prevalence of mental health disorders in young people, relatively few of those in need access timely, evidence-based treatment within specialist child and adolescent services (Frith 2017; Essau 2005). Increasingly, it is recognized that support for young people's mental health must be broader than specialist mental health services, encompassing schools alongside other services (Frith 2017; Department of Health 2015). There has been a recent increase in the number of secondary school exclusions in the UK, suggesting that schools are not able to appropriately address challenging behaviour in a classroom setting (Department of Education 2018). Over the last 20 years school-based mental health prevention programmes and interventions have become increasingly prevalent (Weissberg, Kumpfer, and Seligman 2003), with many young people receiving help for their social, emotional and behavioural needs within school settings (Hoagwood et al. 2007; Stormont, Reinke, and Herman 2009).

There is an increased expectation within the UK for teachers in schools to have responsibility for identifying young people with mental health difficulties and referring them forward to appropriate services (Department of Health and Department of Education 2017). The amount of time teachers spend in contact with students makes them well placed to notice symptoms and behaviours associated with anxiety, depression and other common mental health problems, such as irritability, social withdrawal and changes in concentration (Puura et al. 1998; Chatterji et al. 2004; Ginsburg and Drake 2002). Teachers are in an ideal position to refer and signpost students to mental health care services (Fazel et al. 2014; Schwean and Rodger 2013) as they are often the first point of contact for young people and parents who are worried about their child's emotional wellbeing (Ford et al. 2008; Sax and Kautz 2003). Previous studies have shown that increased emotional support to students by teachers is associated with reductions in students' behaviour problems and depressive symptom scores (Way, Reddy, and Rhodes 2007; Undheim and Sund 2005; Joyce and Early 2014).

As well as signposting, identifying and supporting young people, teachers may also deliver universal mental health interventions within the school setting. Many mental health educational prevention programmes in school are teacher-led, with $40.8 \%$ of interventions including teacher involvement, and $18.4 \%$ of interventions having teachers as the sole deliverer of content (Franklin et al. 2012).

Despite these responsibilities, teachers are not required to learn about and understand mental health disorders as part of their initial training (Shepherd et al. 2013) and many have a limited understanding of the link between school exclusion and mental health difficulties (Nash, Schlösser, and Scarr 2016). Teachers typically have limited access to support and supervision from professionals with expertise around mental health (Sharpe et al. 2016).

In a survey of teachers, 99\% considered acknowledging and managing their students' mental health needs to be part of their role (Roeser and Midgley 1997). In many studies, teachers have described mental health education (Graham et al. 2011) or the management of mental health problems in the classroom as being very important (Walter, Gouze, and Lim 2006). Many teachers acknowledge their ability to identify mental health problems in the classroom (Rothì, Leavey, and Best 2008) and the link between academic and emotional health outcomes (Kidger et al. 2009). Similarly, the majority of teachers believe that schools should be a place where mental health issues are addressed (Reinke et al. 2011).

Previous qualitative and quantitative studies with teachers have highlighted the call from school staff for in-depth specialised mental health training (Graham et al. 2011; Moon, Williford, and Mendenhall 2017; Rothì, Leavey, and Best 2008; Walter, Gouze, and Lim 2006). Without training, teachers have low confidence in their knowledge and ability to recognise mental health problems, or to provide support and manage emotional difficulties in the classroom (Moor et al. 2007; Roeser and Midgley 1997; Cohall et al. 2007). Teachers have expressed helplessness resulting from the perceived inability to help their students (Kidger et al., 2009; Shelemy, Harvey, and Waite, under review). 
In one qualitative study in the UK, school teachers expressed concern about the realistic implementation of mental health training, such as finding an appropriate time in a busy school schedule and transferring what is learnt into a classroom setting (Rothì, Leavey, and Best 2008). Similarly, teachers have reported that previous teacher-led interventions fail to account for their time, pressure and ability to flexibly and continuously commit to the manualised program (Taylor et al. 2014). Poor sustainability of teacher-led interventions may be due to low levels of acceptability for teachers (Han and Weiss 2005).

Existing mental health training programmes need to evaluate their acceptability to teachers and focus their materials on teachers' needs. In several teacher-led mental health interventions, adherence to programme manuals is low. For example in one study, only $47 \%$ of the core items of the intervention were delivered satisfactorily by the teacher facilitators (Gillham et al. 2007). In the BeyondBlue teacher-led program, 70-74\% of the 16 planned lessons were delivered fully by secondary school teachers (Sawyer et al. 2010). One possible explanation for this may be that the training and resources provided for teachers failed to be adaptable and account for teachers' own needs and time restrictions. Research should be done to learn more about the causes behind poor adherence to identify ways that teacher training can be more engaging and better utilised in the classroom.

Collaboration and consultation with teachers is necessary to properly develop schoolbased mental health services, programs and whole-school changes (Lynn, McKay, and Atkins 2003; Rothì, Leavey, and Best 2008). It is crucial that training programs are developed with a clear understanding of the attitudes and requirements of those delivering them in order for them to be successfully implemented (Graczyk et al. 2006; Han and Weiss 2005), as teachers are experts in understanding their classroom, school structure and students' difficulties (Dupaul, Weyandt and Grace, and Janusis 2011; Rothì, Leavey, and Best 2008). Similarly, effective, engaging and evidence-based training for teachers must be designed with a thorough knowledge of what school staff need and would like (Reinke et al. 2011).

Previous studies have demonstrated the value of consultation with teachers to successfully develop school-based interventions. In one study, academic and motivation outcomes for young people with ADHD were improved following a collaborative consultation between researchers, school psychologists and teachers (DuPaul et al. 2006). The identification of what teachers judged feasible and effective via a 'problem identification interview' was a critical aspect of intervention design (DuPaul et al. 2006). This study aims to mirror this approach by consulting teachers about what they need from training to be able to successfully support students with mental health difficulties.

There is not yet an in-depth analysis of what practical ideas and tools teachers actually need and want regarding mental health support and training. Focus groups are an effective qualitative approach that can generate a wide range of views on an issue (Underhill and Olmsted 2003). In comparison to one-to-one interviews, focus groups harness the group dynamic enabling ideas to be explored and developed. This qualitative study uses focus groups and thematic analysis to better understand teachers' wants, needs and opinions around the mental health needs in schools, and the resources and training that would be necessary.

The research aims of this study are to (i) better understand what teachers would like from mental health resources and training, (ii) explore their opinions of different modes of delivery (by allowing them to sample various resources), (iii) identify factors that teachers feel help and obstruct the provision of good support to students.

\section{Method}

The present study was conducted following established criteria for rigour in qualitative research (Denzin and Lincoln 1994), and used the COREQ checklist for reporting (Tong, 
Sainsbury, and Craig 2007) (Appendix A). Ethical approval for the study was obtained from the University of Reading Research Ethics Committee.

\section{Participants}

Participants were eligible for inclusion if they were currently practicing secondary school teachers in the UK. There were no exclusion criteria. Nine focus groups with the recommended four to eight participants (Howitt 2016) were conducted in nine schools across the UK between October 2016 and January 2017. Forty-nine teachers took part in the study. 33 $(67 \%)$ of participants had never received mental health training before, while $10(20 \%)$ had taken part in a certified course (including Mindfulness, Attachment Training, Mental Health First Aid, Art Psychotherapy and Support Work training). The remaining 6 (12\%) participants reported that they had received a single session of mental health training previously. The sample characteristics are presented in more detail in Table 1.

\section{[Table 1 here]}

\section{Sampling}

Advertisements about the study were shared and distributed via online social media (Twitter, Facebook) from the university and authors' accounts. Social media users shared the advertisements to reach a wide audience. Pastoral leads (e.g. Special Educational Needs CoOrdinators, Assistant Headteachers) of schools who saw the advertisement online contacted the lead researcher to register their interest in participating the study. Of the eighteen pastoral leads that got in contact, five were excluded from the study as they were based in primary schools, and nine were purposively sampled to reflect different location of schools (urban vs rural), socio-economic areas, type of institution (state-funded vs private) and sex of students (single-sex or co-educational) using a multiple category design (Howitt 2016). The selected schools were located in five different counties (Wiltshire, Berkshire, Greater London, Hertfordshire, Flintshire) across three regions of the UK (South East England, South West England, North Wales). The pastoral lead helped organise and recruit teachers within their school to attend the focus group. Participants were selected by the pastoral leads within each school based on availability and interest in contributing to the focus group. Focus groups were conducted until response saturation was judged by the lead author to have been reached (Braun and Clarke, 2013), as data analysis and collection were completed concurrently.

\section{Procedure}

Focus groups were moderated by the male lead author, a $\mathrm{PhD}$ student trained in qualitative research methods at the University of Reading. The interviewer had no prior relationship with the participants before the study. An undergraduate placement student took notes during each session with the aims of ensuring all participants had an opportunity to contribute to the discussion and recording field notes about any non-verbal behaviour by members of the group. This information was given to the focus group moderator during the focus group break.

Interviews took place in a private room in each school after the school day had finished to ensure convenience for the participants and a quiet environment. Participants were told the research aims of the study and that all data would be anonymised. Informed written consent was obtained from all individuals before participating. Participants were asked to fill out a brief demographic questionnaire at the beginning of the session about their age and length of 
teaching experience (summarised in Table 1). Participants were all teachers in the school where the interview was conducted and so knew each of the other members of the group.

A semi-structured topic guide was used to direct the focus group. Questions were based on previous qualitative research of teachers' experiences and opinions about mental health in schools (Kidger et al. 2009; Shelemy et al. under review). This guide was piloted with four secondary school teachers to ensure clarity and validity (accessed via Appendix B).

Each focus group discussion addressed three aims: (1) teachers' needs and opinions regarding mental health provision within school, (2) teachers' views on three independent mental health online resources online, and (3) methodology of mental health training and a review of the online resources. Focus groups lasted between 1.5 to 2 hours with a break, including 20 minutes to access the online resources.

The three online resources were selected because they all provided teaching on mental health in schools, are good exemplars of different learning mediums (text, video and an interactive programme), and had no affiliation to any of the researchers. MindEd, a UK government-funded educational free online resource for professionals working with teachers is a text-based programme available throughout the UK (MindEd, n.d.). FutureLearn CognitiveBehavioural Therapy (CBT) Anxiety and Depression course is a massive open online course (MOOC) designed by and delivered through the University of Reading and involves a mixture of video-based learning and text (FutureLearn, n.d.). The final resource was the demo version of Kognito (Kognito, n.d.), an animated interactive program that aims to train teachers on how to support and have a conversation with students about their mental health.

\section{Data Analysis}

Focus groups were audio-recorded and transcribed by the lead author. The computer software package NVivo 10 (NVivo 10 2014) was used to facilitate coding of the transcribed data. Data analysis followed guidelines for thematic analysis from Braun and Clarke (2013). The lead researcher (LS) read and re-read each transcript and field notes to ensure a high level of familiarisation with the data. Transcripts were then annotated and coded into nodes. Two undergraduate placement students also added nodes to several of the transcripts which were compared with the lead author's analysis to ensure important nodes were not missed. Following this stage, nodes were grouped into key presenting themes by the lead author. A consultation and meeting with the two further researchers $(\mathrm{KH}$, an experienced qualitative researcher and PW, an experienced researcher into young people's mental health and a clinician) helped classify the data into more functionally distinct and independent subordinate and superordinate themes.

\section{Results}

Four superordinate themes were generated via analysis and are presented in Table 2. The superordinate and subordinate themes are presented in two broad areas: teacher training and external changes. These represent how the focus groups were structured, with the first emphasising what should be done to improve teacher training, and the other focusing on the external changes that can help participants cope with students' mental health difficulties within school. Broadly across the groups there was unanimity for each of the themes. The themes are explored in greater depth below.

[Table 2 here] 


\section{Identifying and preventing rather than solving}

Many participants wanted advice on how to identify mental health problems in their students and how to prevent a situation from worsening, rather than training in how to provide longterm support for students. When comparing the field notes of focus groups, participants in schools with a dedicated counselling service appeared to be less enthusiastic about receiving mental health training than the other groups.

\section{Learning how to identify students' difficulties}

Participants discussed the need for training to identify whether a student is at risk and whether their mental health or behaviour is a cause for concern. Whilst many participants felt comfortable with identifying clear visible signs, such as self-harm scars, many wanted guidance on noticing more subtle indications of mental health problems in their students.

The warning signs, I'd like to learn a lot more because some mental health issues are quite obvious to spot, but then others less so. You might see positive traits in somebody but really they're masking something that's wrong. - State-funded, urban, co-educational

A repeated suggestion across the focus groups was to have a list of key indicators to help with identifying warning signs.

I think it is quite good to have a print out of a crib sheet actually with a reminder of what you're looking out for. Something that you and other teachers can put in their planners, just something there to refer to. - State, urban, girl's school

\section{Desire to prevent students' mental health from worsening}

When faced with a student who is struggling, many of the participants described how they would use their common sense and instinct to try and help. Some participants were unsure whether they do the right thing in these situations and argued that that without guidance or training, they could be worsening a students' mental health. Collectively participants wanted advice on the correct and incorrect things to say and do to help students.

At the same time, we don't know when to leave things or when to let things go or when to intervene. Do we make things worse? Are we making something out of which is in fact a natural progression? - State, urban, co-educational

Participants asked for advice about the right thing to do in circumstances where a student is in immediate risk of distress or harm, such as during a panic attack. Participants wanted guidance and training on how to contain and support a student prior to expert help being provided.

In the same way first aid training is about trying to stop a situation worsening ... I would like to know two or three key things that would not let a situation escalate, which would be a holding position until the right people can be brought along. - Private, urban, co-educational 
Participants from the focus groups consistently spoke about a societal expectation that they will have responsibility over the wellbeing of their students. Despite this, many of the participants argued that they consider their role a purely academic one and felt that it would be preferable for "experts" with appropriate training to provide support to their students around mental health All of the focus groups emphasised how training should not include therapeutic strategies to improve a young person's mental health, and that the role of the teacher should not be seen as that of a therapist or social worker.

I don't see it as a responsibility to advise them on how to improve it, I think someone else has the expertise to do that and I would feel uncomfortable doing that ... I think that clearly in school we have to deal with things at an initial level. - State-funded, urban, co-educational

Participants mentioned that their role should be viewed as educational and preventative. Training should focus on how to educate students around mental health, ideally before problems begin.

I think we have a duty of care, not a duty of cure. Within that duty of care we have a duty, not put out the fire but to educate them first, which is what we're trying to do. We have been trying to teach them and help them and how to recognise them [mental health problems] early on and I think that's really something that needs to be improved. - State-funded, urban, co-educational

\section{The need for training that has a real-world application}

Participants emphasised the importance of mental health training being focused on providing resources and examples that are applicable to the classroom. They recommended that training should contain relevant case studies, resources and strategies that can be easily adapted and used within the school environment.

\section{Training that teaches practical strategies}

Participants in all groups emphasised the need for training to be focused on practical strategies that can be implemented in their classroom. Whilst some participants found previous mental health training to be useful, others disagreed and found that talks they have attended have commonly focused on descriptive explanations of mental health issues, to the detriment of providing useful and practical advice.

I think with any trained teachers, they want to come away with practical, achievable things they can do in their classroom that'll make a difference. The frustration is always from wishy-washy talks where you come away thinking "there's no way that's relevant to me and there's no way that'll have any impact in my classroom". - State, urban, co-educational

Participants described wanting a concrete list of strategies that can be used and that teachers can easily refer to.

One of the things I would think about is having what strategies to use so ... a definitive list with something like if this happens then you could do this. - State, rural, co-educational 


\section{Receiving adaptable resources and training}

In some of the focus groups, participants described the need for teachers to be able to adapt any resources and lesson plans to make it relevant to the mental health issues faced by their students, as well as ensuring the content is age-appropriate for the specific year groups.

It can't be a one-size-fits-all but maybe tailor-made for different years, dependent on what children are potentially likely to experience in those. Because otherwise year 10 and year 11 will put it off they'll say "it's not for me, this is little kids stuff". - State, rural, co-educational

Adaptable materials enable teachers to feel comfortable with the material that they are delivering.

I don't think that I've ever downloaded the lesson plan from any sort of charity or anything, or even an assembly that I haven't personalised, to make it suitable for our school and so actually, I know exactly what I'm talking about. - State, rural, co-educational

\section{Incorporation of illustrative case studies}

In several groups, especially those in which individuals had been critical of previous mental health training, participants described case studies as being a useful tool to understand how to find practical solutions to help students within a school environment.

I want case studies around issues that have happened in schools and learn how they have been dealt with. What has the outcome been for the student involved, the family? What have the staff learnt from dealing with it? That would be really useful, what have staff that have been involved picked up from that experience and what would they do differently next time. If we had those case studies looking at all the different angles that would be great. - State, urban, coeducational

These participants described how they would like to have real stories from young people to better understand the nature of their mental health problems and what they are going through.

I think it's also good to have example of people who are suffering from whatever the issue is, talking about it and what made a difference to them. So videos, somebody actually talking about what worked for them. - State-funded, urban, co-educational

\section{The need for training to be engaging and active}

The accessibility of training is crucial to enable teacher engagement, retention and interest. There was a high level of discrepancy amongst participants within each group as to which style of learning they preferred (e.g. interactive, audio/visual, group discussions). Participants typically resolved these differences by agreeing that training should contain a mix of teaching styles to appeal to different learners. Generally, the training courses that they valued most were 
interactive, simple and led by someone who participants considered to be an expert in mental health.

\section{Interactive training}

Participants recommended all training should be interactive, promote discussion and require feedback from the audience.

I think if you have the expert talking to you in front of you, giving you some video clips of a mocked up class ... then you've got an opportunity to stop and discuss at certain points with the group with the professionals around you, I think that would be a useful thing to do. - State, urban, co-educational

If delivered online or through videos, some participants recommended including compulsory questions to check that the person had understood the material and to encourage them to pay attention.

I think a quick video and some way of checking you've understood it. Even for me just watching that video, I would have liked a few questions just to check I have understood what the key learning points were. - State, urban, coeducational

\section{Simplicity and variation in training method}

Participants spoke about how online mental health training should have variation in the style and allow users to have the option of choosing their preferred form of learning.

I think that's the only way you're going to hit teachers, is a combination: have all of them. Have multiple avenues, have the kind of stuff that we put into our lessons. It's got to be interactive and audio-visual. - Private, urban, coeducational

There was debate amongst participants about the three resources shown, with some finding online learning difficult, whilst others finding content engaging and useful.

For me, online training doesn't work, that's just my personal view. I can't be trusted to go onto a computer in the evenings or any other point and stay focused on that one bit of information on the screen and the activities, it just doesn't work. I need to be in a room with people doing it interactively. - State, rural, coeducational

The time and work constraints that teachers face meant that training resources need to be short and direct, with educational resources being to the point and not allowing teachers' attention to wander.

You know just 30 second clips. We like to move on. We don't have a lot of time. We won't want to be sat there for 10 minutes watching a video. Teachers are like children really, we have to be entertained. - State, urban, girl's school 
Some participants described being unsure about the quality of the training programmes they had previously received. When shown resources delivered by individuals with a clinical or professional qualification, participants responded well and found the content more engaging.

Having an expert come in, I always prefer. Actually being able to speak to someone who you know has experience with dealing with students that age is essential. - State, urban, co-educational

Similarly, many participants felt that all training and resources should be backed up by evidence showing the previous effectiveness and relevance of the training.

I think it has to be backed up by evidence, you need to prove why it is worth doing otherwise we won't do it. We need evidence as to what this is and how it can improve your teaching and your lessons and the student's grades etc. Hard facts as evidence. - State, urban, girl's school

Several participants spoke about the interest in training that resulted in an accreditation or certificate as part of their continued professional development (CPD) as a motivation for receiving and being more attentive during training.

The certificate part is important because we have to log training and it just means that you have that evidence and you have your professional portfolio that is transferable from school to school. - State, urban, co-educational

\section{Changes that are needed outside the classroom}

The following themes represent areas beyond the classroom that participants felt needed to be in place in order to provide good support to students. The discussions focused mainly on having clearly defined referral routes and guidance for what to do when passing on concern about a student.

\section{Clear within-school mental health communication strategy}

The majority of the schools in the study had a well implemented mental health communication strategy, including clear reminders of procedures for signposting students to appropriate services. Participants in these schools emphasised the importance of understanding how to refer a student to other members of staff within the school for support around their mental health difficulties, such as pastoral staff or heads of house.

It's all the little things, like on all the back of our lanyards, a very clear instruction to members of staff about what they might do if a child discloses ... I don't think there would be a single member of staff that wouldn't know that. - State-funded, urban, co-educational

\section{Approachable pastoral school staff}

In contrast to safeguarding procedures, participants often felt unsure whether they had done the right thing when informing other school staff about a student they were worried about. 
Participants across all groups emphasized the need and usefulness of pastoral staff that are known to everyone and are available to speak to.

And the SENCOs [Special Educational Needs Coordinator] are very visible, they're all in an office together, they're not office bound, they are out and about all the time. The people are very comfortable, and trust making referrals to them or just seeking advice from them. They're very well-established members of staff, very approachable. - State, rural, co-educational

Similarly, many participants mentioned the need for acknowledgement and reassurance from the member of staff they have referred the student to.

You want that immediate recognition that you've done the right thing. - State, urban, co-educational

\section{Training and informing parents/carers}

Several participants emphasised the need for parents to be informed in young people's mental health. Parents were described as often dismissive of their child's mental health problems. The teachers wanted to learn how they themselves might educate and inform parents, in a manner that was not patronising or blaming.

One of the challenges I think is to get parents on board. We have conversations with parents and they're not necessarily keen to engage and they don't see it as a mental health problem. And you try and word it as well as you can and the parents aren't taking it seriously, like saying "Oh she's just being a drama queen". It becomes very challenging because there's a limit to what you can do. I think it's how we educate parents and families as well. - State, urban, coeducational

\section{Improved communication with Child and Adolescent Mental Health Services (CAMHS)}

A frequent frustration expressed by participants was the lack of communication from CAMHS. Many of the discussions mentioned how CAMHS staff are often perceived to be unable to provide useful information or advice to staff about their students.

Very often we don't get that much feedback that often. When you know a child has been diagnosed with mental health concern issue, then they've been given therapeutic support ... what impact is that going to have on them? And how as a school can we support them? It's a big gap. We don't get that advice. I don't recall ever really having free form communication with CAMHS. ... There needs to be more sharing of information. - State-funded, urban, co-educational

\section{Discussion}

There is a demand from both teachers and governmental bodies for school staff to be trained in how to support young people around mental health (Department of Health 2015; Rothì et al. 2008; Shelemy et al. under review). This study describes findings from nine focus groups with 49 secondary school teachers across the UK. Participants were asked to describe what mental health training, support and resources they would need in order to successfully support students 
around mental health difficulties. The main themes that arose were that training should be focused on preventing rather than solving a students' problem, be engaging and active, and have a real world application. Participants also commented on the need for better communication with external CAMHS services, as well as guidance on what makes a successful within-school mental health communication strategy. Many of the focus groups discussed the need to also educate parents about mental health.

Several of these themes are consistent with those found in previous studies of teachers' attitudes towards mental health. Participants' recognition of the need for teacher training in mental health is consistent with findings from previous studies (e.g. Graham et al. 2011; Walter et al. 2006). Many participants described not wanting to take on the role of therapist and did not feel qualified to speak to young people in depth about their problems. This is echoed in previous consultations of teachers' experiences of mental health in the classroom (Department of Health and Department of Education 2018; Shelemy et al. under review). Previous studies have also found that teachers want discussions of real case studies paired with practical guidance on how to help students who are struggling or disruptive (Vieira et al. 2014) and expert-led training from a trusted and certified source (Walter et al., 2006).

Whilst participants in each of the focus groups disagreed over the ideal style of learning, particularly when looking at online resources, the consensus was training that is expert-led with a mix of teaching methods is most likely to appeal to a broad group of teachers. Mental health training for teachers should be focused heavily on practical strategies and relevant case studies and less centred on vague information that cannot be applied to the classroom.

These findings are particularly relevant in light of the recent Green Paper in the UK announcing future funding for mental health awareness training for "every secondary school" and for 'Designated Senior Leads' (Department of Health and Department of Education 2017). Whilst this initiative is promising, responses to the paper have expressed concerns that the training should be "high quality", "based on evidence and good practice" and include "manageable ways that are adaptable to different types and sizes of schools" (Department of Health and Department of Education 2018). For this training to be successful, it is crucial that the concerns of teachers are considered. As such, we have generated a checklist (Table 3) that arises directly from the findings of the current study. This can be used to ensure mental health training meets the needs of teachers, thus increasing their likely engagement.

\section{[Table 3 here]}

The strength of this study is that it is a valid exploration of the needs and wants of teachers regarding mental health in schools; the research was conducted by experienced qualitative researchers and closely followed guidance by Braun and Clarke (2013). The study meets the criteria of the COREQ guidelines for rigorous reporting of qualitative research (Appendix A) (Tong, Sainsbury, and Craig 2007). All of the participants were current teachers with experience of the challenges faced supporting students in a school environment. Whilst there was some variation in opinions within and across groups, the themes described were consistent across all those who participated. Purposive sampling resulted in school variation on three key dimensions; geographical location within the UK; urban and rural areas, statefunded and privately-funded.

There are several limitations of the present research that should be acknowledged. Whilst a variety of schools were contacted about the study, with the hope of recruiting schools with varying Ofsted ratings, the schools that participated were all rated by Ofsted as 'Good' or 'Outstanding', thus representing schools that are performing well on academic, social and behavioural outcomes. The mental health and behavioural problems presented in these schools may differ in schools with lower Ofsted ratings and teachers in these schools may have different 
training requirements. Participants were selected by the pastoral leads within each school and it is plausible that many of the participants in this study were teachers who were known to have an interest in mental health and believed that training played a crucial role in school staff professional development. The views of teachers who do not feel that mental health is part of their role may not have been captured in this study, resulting in data that is shaped around the presumption that mental health in schools is a relevant topic.

It is important to acknowledge the biases of the researchers and their potential to shape the analysis. The analysis was conducted, compared and contrasted by several different researchers whose varying background and experience will have informed their opinions and beliefs about mental health training in schools. For example, the lead author believes that mental health training should be provided for school staff and collaborates with a charity focused on young people's mental health training, while the second author $(\mathrm{KH})$ is an academic health psychologist with an interest in psychological wellbeing and intervention, and the third author (PW) is a clinical psychologist with an interest in young people's mental health.

Field notes from the current study indicate that teachers from schools with funding for a dedicated counselling support service were not as passionate about receiving training compared to other schools. It is possible that these schools are in less need of training than schools, perhaps because they have more readily available resources and additional staff to help young people with mental health problems. Future studies should investigate similarities and differences between different school types, areas, academic outcomes and socio-economic status to identify additional needs faced by schools regarding more specific vulnerabilities.

\section{Conclusion}

Mental health training for teachers must be practical, simple and interactive. We have identified key factors from focus groups with teachers that highlight the main areas that school training interventions should cover and have presented them as a checklist that can easily be applied by developers to interventions. Future mental health programmes should use these criteria to ensure that training is directly relevant and pragmatic for schools.

\section{Acknowledgments}

We would like to thank the teachers who took part in this research for their help. The research materials can be accessed by contacting the corresponding author.

\section{Declaration of interest and funding details}

The PhD of the lead researcher is funded by The Charlie Waller Memorial Trust, a charity aiming to improve mental health in young people. The Trust had no involvement in the research process, from study design to submission. The authors report no conflicts of interest. The authors alone are responsible for the content and writing of this article.

\section{References}

Braun, Virginia, and Victoria Clarke. 2013. Successful Qualitative Research : A Practical Guide for Beginners. SAGE.

Chatterji, Pinka, Christine M Caffray, Maura Crowe, Linda Freeman, and Peter Jensen. 2004. "Cost Assessment of a School-Based Mental Health Screening and Treatment Program in New York City." Mental Health Services Research 6 (3): 155-66.

Cohall, Alwyn T, Renee Cohall, Bonnie Dye, Sheila Dini, Roger D Vaughan, and Susan 
Coots. 2007. "Overheard in the Halls: What Adolescents Are Saying, and What

Teachers Are Hearing, about Health Issues." The Journal of School Health 77 (7): 34450. https://doi.org/10.1111/j.1746-1561.2007.00218.x.

Denzin, Norman K., and Yvonna S. Lincoln. 1994. Handbook of Qualitative Research. Sage Publications.

Department of Education. 2018. "Permanent and Fixed Period Exclusions in England: 2016 to 2017." Accessed December 10, 2018.

https://assets.publishing.service.gov.uk/government/uploads/system/uploads/attachment _data/file/726741/text_exc1617.pdf.

Department of Health. 2015. "Future in Mind - Promoting, Protecting and Improving Our Children and Young People's Mental Health and Wellbeing." Accessed December 10, 2018.

https://assets.publishing.service.gov.uk/government/uploads/system/uploads/attachment _data/file/414024/Childrens_Mental_Health.pdf.

Department of Health and Department of Education. 2017. "Transforming Children's and Young People's Mental Health Provision: A Green Paper." Accessed December 10, 2018.

https://assets.publishing.service.gov.uk/government/uploads/system/uploads/attachment _data/file/664855/Transforming_children_and_young_people_s_mental_health_provisio n.pdf.

Department of Health and Department of Education. 2018. "Government Response to the Consultation on Transforming Children and Young People's Mental Health Provision: a Green Paper and Next Steps." Accessed December 10, 2018.

https://assets.publishing.service.gov.uk/government/uploads/system/uploads/attachment _data/file/728892/government-response-to-consultation-on-transforming-children-andyoung-peoples-mental-health.pdf.

DuPaul, George J., Asha K. Jitendra, Robert J. Volpe, Katy E. Tresco, J. Gary Lutz, Rosemary E. Vile Junod, Kristi S. Cleary, Lizette M. Flammer, and Mark C. Mannella. 2006. "Consultation-Based Academic Interventions for Children with ADHD: Effects on Reading and Mathematics Achievement." Journal of Abnormal Child Psychology 34 (5): 633-46. https://doi.org/10.1007/s10802-006-9046-7.

Dupaul, George J, Lisa L Weyandt \& Grace, and M M Janusis. 2011. “Theory Into Practice ADHD in the Classroom: Effective Intervention Strategies" 50 (1): 35-42. https://doi.org/10.1080/00405841.2011.534935doi.org/10.1080/00405841.2011.534935.

Essau, Cecilia A. 2005. "Frequency and Patterns of Mental Health Services Utilization among Adolescents with Anxiety and Depressive Disorders." Depression and Anxiety 22 (3): 130-37. https://doi.org/10.1002/da.20115.

Fazel, Mina, Kimberly Hoagwood, Sharon Stephan, and Tamsin Ford. 2014. "Mental Health Interventions in Schools in High-Income Countries." The Lancet Psychiatry 1 (5): 37787. https://doi.org/10.1016/S2215-0366(14)70312-8.

Ford, Tamsin, Helena Hamilton, Howard Meltzer, and Robert Goodman. 2008. "Predictors of Service Use for Mental Health Problems Among British Schoolchildren." Child and Adolescent Mental Health 13 (1): 32-40. https://doi.org/10.1111/j.14753588.2007.00449.x.

Franklin, Cynthia G.S., Johnny S. Kim, Tiffany N. Ryan, Michael S. Kelly, and Katherine L. Montgomery. 2012. "Teacher Involvement in School Mental Health Interventions: A Systematic Review." Children and Youth Services Review 34 (5): 973-82. https://doi.org/10.1016/J.CHILDYOUTH.2012.01.027.

Frith, Emily. 2017. "Access and Waiting Times in Children and Young People's Mental Health Services - The Education Policy Institute.” Education Policy Institute. 
https://epi.org.uk/publications-and-research/access-waiting-times-children-youngpeoples-mental-health-services/.

FutureLearn. n.d. "Understanding Depression and Low Mood in Young People." Accessed December 10, 2018. https://www.futurelearn.com/courses/depression-young-people.

Gillham, Jane E., Karen J. Reivich, Derek R. Freres, Tara M. Chaplin, Andrew J. Shatté, Barbra Samuels, Andrea G. L. Elkon, et al. 2007. "School-Based Prevention of Depressive Symptoms: A Randomized Controlled Study of the Effectiveness and Specificity of the Penn Resiliency Program." Journal of Consulting and Clinical Psychology 75 (1): 9-19. https://doi.org/10.1037/0022-006X.75.1.9.

Ginsburg, Golda S., and Kelly L. Drake. 2002. "School-Based Treatment for Anxious African-American Adolescents: A Controlled Pilot Study." Journal of the American Academy of Child \& Adolescent Psychiatry 41 (7): 768-75. https://doi.org/10.1097/00004583-200207000-00007.

Graczyk, Patricia A, Celene E Domitrovich, Meg Small, and Joseph E Zins. 2006. "Serving All Children: An Implementation Model Framework." School Psychology Review 35 (2): 266-74.

Graham, Anne, Renata Phelps, Carrie Maddison, and Robyn Fitzgerald. 2011. "Supporting Children's Mental Health in Schools: Teacher Views." Teachers and Teaching 17 (4): 479-96. https://doi.org/10.1080/13540602.2011.580525.

Han, Susan S., and Bahr Weiss. 2005. "Sustainability of Teacher Implementation of SchoolBased Mental Health Programs." Journal of Abnormal Child Psychology 33 (6): 66579. https://doi.org/10.1007/s10802-005-7646-2.

Hoagwood, Kimberly E., S. Serene Olin, Bonnie D. Kerker, Thomas R. Kratochwill, Maura Crowe, and Noa Saka. 2007. "Empirically Based School Interventions Targeted at Academic and Mental Health Functioning." Journal of Emotional and Behavioral Disorders 15 (2): 66-92. https://doi.org/10.1177/10634266070150020301.

Howitt, Dennis. 2016. Introduction to Qualitative Research Methods in Psychology. Third edit. Harlow: Pearson.

Joyce, Hilary D., and Theresa J. Early. 2014. "The Impact of School Connectedness and Teacher Support on Depressive Symptoms in Adolescents: A Multilevel Analysis." Children and Youth Services Review 39 (April): 101-7. https://doi.org/10.1016/j.childyouth.2014.02.005.

Kidger, Judi, David Gunnell, Lucy Biddle, Rona Campbell, and Jenny Donovan. 2009. "Part and Parcel of Teaching? Secondary School Staff's Views on Supporting Student Emotional Health and Well-being." British Educational Research Journal 36 (6): 91935. https://doi.org/10.1080/01411920903249308.

Kognito. n.d. "At Risk for PK-12 Educators." Accessed December 10, 2018. https://kognito.com/products/at-risk-for-high-school-educators.

Lynn, C. J., M. M. McKay, and M. S. Atkins. 2003. "School Social Work: Meeting the Mental Health Needs of Students through Collaboration with Teachers." Children \& Schools 25 (4): 197-209. https://doi.org/10.1093/cs/25.4.197.

MindEd. n.d. "Mentel Health and Wellbeing." Accessed December 10, 2018. https://www.minded.org.uk/.

Moon, Jungrim, Anne Williford, and Amy Mendenhall. 2017. "Educators' Perceptions of Youth Mental Health: Implications for Training and the Promotion of Mental Health Services in Schools." Children and Youth Services Review 73 (February): 384-91. https://doi.org/10.1016/J.CHILDYOUTH.2017.01.006.

Moor, Stephanie, Maguire Ann, McQueen Hester, Wells J. Elisabeth, Elton Robert, Wrate Robert, Blair Caroline, et al. 2007. "Improving the Recognition of Depression in Adolescence: Can We Teach the Teachers?" Journal of Adolescence 30 (1): 81-95. 
https://doi.org/10.1016/j.adolescence.2005.12.001.

Nash, Poppy, Annette Schlösser, and Tanya Scarr. 2016. "Teachers' Perceptions of

Disruptive Behaviour in Schools: A Psychological Perspective.” Emotional and

Behavioural Difficulties 21 (2): 167-80.

https://doi.org/10.1080/13632752.2015.1054670.

NVivo Qualitative Data Analysis Software. 2014. QSR International Pty Ltd.

Puura, Kaija, Fredrik Almqvist, Jorma Piha, Irma Moilanen, Tuula Tamminen, Kirsti Kumpulainen, Eila Rasanen, and Anna-Maija Koivisto. 1998. "Children with Symptoms of Depression-What Do the Adults See?" Journal of Child Psychology and Psychiatry 39 (4): 577-85. https://doi.org/10.1111/1469-7610.00353.

Reinke, Wendy M., Melissa Stormont, Keith C. Herman, Rohini Puri, and Nidhi Goel. 2011. "Supporting Children's Mental Health in Schools: Teacher Perceptions of Needs, Roles, and Barriers." School Psychology Quarterly 26 (1): 1-13.

https://doi.org/10.1037/a0022714.

Roeser, Robert W., and Carol Midgley. 1997. “Teachers' Views of Issues Involving Students’ Mental Health.” The Elementary School Journal 98 (2): 115-33. https://doi.org/10.1086/461887.

Rothì, Despina M., Gerard Leavey, and Ron Best. 2008. "On the Front-Line: Teachers as Active Observers of Pupils' Mental Health." Teaching and Teacher Education 24 (5): 1217-31. https://doi.org/10.1016/J.TATE.2007.09.011.

Sawyer, Michael G., Sara Pfeiffer, Susan H. Spence, Lyndal Bond, Brian Graetz, Debra Kay, George Patton, and Jeanie Sheffield. 2010. "School-Based Prevention of Depression: A Randomised Controlled Study of the Beyondblue Schools Research Initiative." Journal of Child Psychology and Psychiatry 51 (2): 199-209. https://doi.org/10.1111/j.14697610.2009.02136.x.

Sax, Leonard, and Kathleen J Kautz. 2003. "Who First Suggests the Diagnosis of AttentionDeficit/Hyperactivity Disorder?” Annals of Family Medicine 1 (3): 171-74. https://doi.org/10.1370/AFM.3.

Schwean, Vicki, and Susan Rodger. 2013. "Children First." Canadian Journal of School Psychology 28 (1): 136-66. https://doi.org/10.1177/0829573513475773.

Sharpe, Helen, Tamsin Ford, Suzet Tanya Lereya, Chris Owen, Russell M. Viner, and Miranda Wolpert. 2016. "Survey of Schools' Work with Child and Adolescent Mental Health across England: A System in Need of Support." Child and Adolescent Mental Health 21 (3): 148-53. https://doi.org/10.1111/camh.12166.

Shelemy, Lucas, Kate Harvey, Polly Waite. Under review. "Secondary school teachers' experiences of supporting mental health."

Shepherd, J, S Dewhirst, K Pickett, J Byrne, V Speller, M Grace, P Almond, D Hartwell, and P Roderick. 2013. Factors Facilitating and Constraining the Delivery of Effective Teacher Training to Promote Health and Well-Being in Schools: A Survey of Current Practice and Systematic Review. Factors Facilitating and Constraining the Delivery of Effective Training to Promote Health and Well-Being in Schools: A Survey ofcurrent Practice and Systematic Review. NIHR Journals Library. https://doi.org/10.3310/PHR01020.

Stormont, Melissa, Wendy M. Reinke, and Keith C. Herman. 2009. "Introduction to the Special Issue: Using Prevention Science to Address Mental Health Issues in Schools." Psychology in the Schools 47 (1): n/a-n/a. https://doi.org/10.1002/pits.20447.

Taylor, John A, Rhiannon Phillips, Ellen Cook, Lucy Georgiou, Paul Stallard, and Kapil Sayal. 2014. "A Qualitative Process Evaluation of Classroom-Based Cognitive Behaviour Therapy to Reduce Adolescent Depression.” International Journal of Environmental Research and Public Health 11 (6): 5951-69. 
https://doi.org/10.3390/ijerph110605951.

Tong, A., P. Sainsbury, and J. Craig. 2007. "Consolidated Criteria for Reporting Qualitative Research (COREQ): A 32-Item Checklist for Interviews and Focus Groups."

International Journal for Quality in Health Care 19 (6): 349-57. https://doi.org/10.1093/intqhc/mzm042.

Underhill, Christina, and Murrey G. Olmsted. 2003. "An Experimental Comparison of Computer-Mediated and Face-to-Face Focus Groups.” Social Science Computer Review 21 (4): 506-12. https://doi.org/10.1177/0894439303256541.

Undheim, Anne Mari, and Anne Mari Sund. 2005. "School Factors and the Emergence of Depressive Symptoms among Young Norwegian Adolescents." European Child \& Adolescent Psychiatry 14 (8): 446-53. https://doi.org/10.1007/s00787-005-0496-1.

Vieira, Marlene A, Ary A Gadelha, Taís S Moriyama, Rodrigo A Bressan, and Isabel A Bordin. 2014. "Evaluating the Effectiveness of a Training Program That Builds Teachers' Capability to Identify and Appropriately Refer Middle and High School Students with Mental Health Problems in Brazil: An Exploratory Study." BMC Public Health 14 (1): 210. https://doi.org/10.1186/1471-2458-14-210.

Walter, Heather J., Karen Gouze, and Karen G. Lim. 2006. “Teachers' Beliefs About Mental Health Needs in Inner City Elementary Schools." Journal of the American Academy of Child \& Adolescent Psychiatry 45 (1): 61-68. https://doi.org/10.1097/01.chi.0000187243.17824.6c.

Way, Niobe, Ranjini Reddy, and Jean Rhodes. 2007. "Students' Perceptions of School Climate During the Middle School Years: Associations with Trajectories of Psychological and Behavioral Adjustment." American Journal of Community Psychology 40 (3-4): 194-213. https://doi.org/10.1007/s10464-007-9143-y.

Weissberg, Roger P, Karol L Kumpfer, and Martin E Seligman. 2003. "Prevention That Works for Children and Youth. An Introduction." The American Psychologist 58 (6-7): 425-32. 
Table 1: Overview of focus group characteristics and demographics of participants.

\begin{tabular}{|c|c|c|c|c|c|c|c|c|c|c|c|}
\hline \multirow[b]{2}{*}{$\begin{array}{l}\text { Focus } \\
\text { Group }\end{array}$} & \multicolumn{4}{|c|}{ Age category } & \multicolumn{3}{|c|}{ Gender } & \multicolumn{4}{|c|}{ Years spent teaching } \\
\hline & $\begin{array}{c}\text { School } \\
\text { description }\end{array}$ & $21-29$ & $30-49$ & $50-60$ & NR & Female & Male & $0-5$ & $6-15$ & $16+$ & NR \\
\hline G1 & $\begin{array}{c}\text { Private, } \\
\text { urban, co- } \\
\text { educational }\end{array}$ & 0 & 2 & 2 & 2 & 2 & 4 & 0 & 3 & 2 & 1 \\
\hline G2 & $\begin{array}{c}\text { State, urban, } \\
\text { co- } \\
\text { educational }\end{array}$ & 0 & 0 & 0 & 6 & 6 & 0 & 0 & 5 & 1 & 0 \\
\hline G3 & $\begin{array}{c}\text { State, urban, } \\
\text { co- } \\
\text { educational }\end{array}$ & 0 & 1 & 1 & 3 & 3 & 2 & 1 & 1 & 1 & 2 \\
\hline G4 & $\begin{array}{c}\text { State, rural, } \\
\text { co- } \\
\text { educational }\end{array}$ & 1 & 3 & 1 & 1 & 4 & 2 & 3 & 2 & 1 & 0 \\
\hline G5 & $\begin{array}{c}\text { State, urban, } \\
\text { co- } \\
\text { educational }\end{array}$ & 2 & 2 & 1 & 3 & 6 & 2 & 2 & 2 & 4 & 0 \\
\hline G6 & $\begin{array}{c}\text { State, urban, } \\
\text { co- } \\
\text { educational }\end{array}$ & 0 & 2 & 1 & 1 & 4 & 0 & 1 & 2 & 1 & 0 \\
\hline G7 & $\begin{array}{c}\text { State, rural, } \\
\text { co- } \\
\text { educational }\end{array}$ & 0 & 2 & 1 & 1 & 4 & 0 & 0 & 1 & 3 & 0 \\
\hline G8 & $\begin{array}{l}\text { State, urban, } \\
\text { girl's school }\end{array}$ & 1 & 2 & 1 & 1 & 5 & 0 & 1 & 2 & 2 & 0 \\
\hline \multirow[t]{2}{*}{ G9 } & $\begin{array}{c}\text { State, rural, } \\
\text { co- } \\
\text { educational }\end{array}$ & 0 & 3 & 0 & 2 & 4 & 1 & 0 & 2 & 3 & 0 \\
\hline & & 4 & 17 & 8 & 20 & 38 & 11 & 7 & 21 & 18 & 3 \\
\hline
\end{tabular}

NR = Not Reported; participants were asked but did not write answer. $\mathrm{G}=$ group. 
Table 2: Superordinate and subordinate themes are presented under descriptive areas and category labels.

\begin{tabular}{|c|c|c|}
\hline \multicolumn{3}{|l|}{ Teacher Training } \\
\hline Category & Superordinate Themes & Subordinate Themes \\
\hline \multirow[t]{3}{*}{$\begin{array}{l}\text { Content of } \\
\text { Training }\end{array}$} & $\begin{array}{l}\text { Identifying and preventing } \\
\text { rather than solving }\end{array}$ & $\begin{array}{l}\text { Learning how to identify students' } \\
\text { difficulties }\end{array}$ \\
\hline & & $\begin{array}{l}\text { Desire to prevent students' mental health } \\
\text { from worsening }\end{array}$ \\
\hline & & Not wanting to take on the role of therapist \\
\hline \multirow[t]{3}{*}{ Style of Training } & $\begin{array}{l}\text { The need for training that } \\
\text { has a real-world } \\
\text { application }\end{array}$ & Teaching that teaches practical strategies \\
\hline & & Receiving adaptable resources and training \\
\hline & & Incorporation of illustrative case studies \\
\hline \multirow[t]{3}{*}{$\begin{array}{l}\text { Accessibility of } \\
\text { Training }\end{array}$} & $\begin{array}{l}\text { The need for training to be } \\
\text { engaging and active }\end{array}$ & Interactive training \\
\hline & & $\begin{array}{l}\text { Simplicity and variation in training } \\
\text { method }\end{array}$ \\
\hline & & $\begin{array}{l}\text { Training that is expert-led, evidence-based } \\
\text { and accredited }\end{array}$ \\
\hline \multicolumn{3}{|c|}{ External Changes } \\
\hline Category & Superordinate Theme & Subordinate Themes \\
\hline \multirow[t]{4}{*}{$\begin{array}{l}\text { School and } \\
\text { Services }\end{array}$} & $\begin{array}{l}\text { Changes that are needed } \\
\text { outside the classroom }\end{array}$ & $\begin{array}{l}\text { Clear within-school mental health } \\
\text { communication strategy }\end{array}$ \\
\hline & & Approachable pastoral school staff \\
\hline & & Training and informing parents/carers \\
\hline & & $\begin{array}{l}\text { Improved communication with Child and } \\
\text { Adolescent Mental Health Services } \\
\text { (CAMHS) }\end{array}$ \\
\hline
\end{tabular}


Table 3: A checklist based on participants' expressed wants and needs of mental health training

\begin{tabular}{|l|l|}
\hline Does your school staff mental health training include ... & \\
\hline How to identify mental health problems and warning signs & \\
\hline How to prevent a situation from worsening & \\
\hline The right and wrong things to say to a student with a mental health problem & \\
\hline How to help a student in the short term & \\
\hline Practical strategies over information about different diagnoses & \\
\hline Resources that can be adapted and tailored by teachers & \\
\hline Materials that are relevant for the issues faced by a targeted age group & \\
\hline Case studies of what worked in different situations & \\
\hline Experiences of actual young people with mental health difficulties & \\
\hline Interactive methods and testing of participants & \\
\hline Engaging and mixed-medium methods of learning & \\
\hline Expert-led material that is evidence-based & \\
\hline How to set up a successful within-school referral system & \\
\hline How to ensure pastoral staff are approachable & \\
\hline How to advise and talk to parents about mental health & \\
\hline How to improve communication with external services & \\
\hline Certification and accreditation & \\
\hline
\end{tabular}

